\title{
LINGUAGEM CORPORAL NA PROMOÇÃO DE RESILIÊNCIA: UMA PRÁTICA EDUCACIONAL COM ACADÊMICOS DO CURSO DE EDUCAÇÃO FÍSICA
}

\author{
Ângela Adriane Schmidt Bersch ${ }^{\mathrm{i}}$ \\ Eliane Lima Piske
}

\begin{abstract}
Resumo: O artigo apresenta a linguagem corporal como mecanismo de proteção e promoção de resiliência em intervenções para formação de acadêmicos de Educação Física de uma Universidade Federal do Sul do Brasil. A pesquisa foi qualitativa e a Grounded Theory e o software Atlas.Ti foram as bases de análise das informações. As intervenções foram realizadas por meio de estratégias pedagógicas com a temática central da linguagem corporal com foco nas emoções e sentimentos dos estudantes. Os resultados na vivência da corporeidade foram apontados como possibilidades de mudanças nas novas aprendizagens e experiências relacionais. Estes podem ser fatores potencializadores da resiliência pela via corpórea pelas evidências de que geraram possibilidades de superação das adversidades de cada um.
\end{abstract}

Palavras-chave: Resiliência, Linguagem Corporal, Educação Física.

\section{BODY LANGUAGE IN PROMOTING RESILIENCE: AN EDUCATIONAL PRACTICE WITH ACADEMICS OF THE PHYSICAL EDUCATION COURSE}

\begin{abstract}
The article presents body language as a protective mechanism that promotes resilience in interventions for Physical Education students of a Federal University of Southern Brazil . The research was qualitative and Grounded Theory and Atlas.ti software are the base for analysis of all information. The interventions were carried out through pedagogical strategies with the central theme of body language focusing on emotions and feelings from students. The results were identified as possibilities of changes, through new learning and relational experiences. These are factors of resilience enhaced the body.that might generate possibilities of overcoming the adversities of each individual.
\end{abstract}

Key-words: Resilience, Body Language, Physical Education.

\section{Introdução}

O presente artigo apresenta a linguagem corporal como mecanismo de proteção para a promoção de resiliência em intervenções educativas para formação de acadêmicos do curso de Educação Física de uma Universidade Federal do Sul do Brasil. O pano de fundo foi composto por dinâmicas lúdicas, cooperativas e vivenciais compartilhadas na disciplina Formação Pessoal pela Via Corporal. O objetivo foi refletir sobre a contribuição da linguagem corporal 
como promotora de mecanismos de resiliência em situações individuais caracterizadas por percepção subjetiva de riscos. A inspiração para as mediações foi a técnica de intervenção Formação Pessoal pela via corporal (BERSCH, 2014). Entretanto, foram necessárias algumas adaptações ao método original, considerando-se o foco da pesquisa, que é oferecer e avaliar uma intervenção promotora de proteção e de resiliência.

Os poucos estudos sobre a resiliência no âmbito da Educação Física se detiveram na temática do esporte. Borges et al., (2006) desenvolveram pesquisa sobre a prática de futsal de meninas. Já Fontes e Brandão (2013) enfocaram a resiliência no esporte de alto rendimento. Outro trabalho relevante e que contribuiu para nossas reflexões aponta o professor de Educação Física como um tutor de resiliência (NEVES et al., 2015). Neste estudo, as autoras afirmam ser o exercício físico, bem como as experiências corporais de forma longitudinal fundamentais para potencializar a identidade corporal do aluno. Vários estudiosos reconhecem a resiliência como um fenômeno comum e presente no desenvolvimento de qualquer ser humano (MASTEN, 2014). Outros destacam a necessidade de cautela no uso naturalizado do termo (MARTINEAU, 1999; YUNES, 2015).

Os autores supracitados afirmam que resiliência muda no decorrer do tempo, de acordo com a cultura, os contextos e a forma como percebem e significam diversos acontecimentos. Além disso, esclarecem que a resiliência não é uma característica inata do indivíduo, ou seja, não nascemos resilientes: desenvolvemos essa capacidade à medida que somos expostos a enfrentamentos de adversidades e reagimos de modo positivo. Assim, tornamos esses conflitos verdadeiros exercícios de crescimento e reflexão pessoal (MASTEN, 2014; MARTINEAU, 1999; YUNES, 2015).

Numa tentativa de síntese, podemos afirmar que a resiliência se refere a processos que produzem respostas positivas, exitosas e prospectivas em indivíduos, grupos ou comunidades. Tais respostas emergem diante de crises, desafios e dificuldades, de forma a resultar em superação de situações adversas, evolução e fortalecimento pessoal, após vivências de experiências negativas e sofridas. Sendo assim, a resiliência não se relaciona a um estado de felicidade ou euforia, nem tampouco de apatia ou acomodação passiva. Portanto tem mais relação com as aprendizagens e competências adquiridas a partir das relações e interações positivas entre o indivíduo, seus pares e demais elementos do contexto em que está inserido (MARTINEAU, 1999; YUNES, 2015).

A resiliência tem ligação com processos e não é elaborada isoladamente por um indivíduo. Portanto, para que a resiliência se efetive, é preciso haver interrelações e outras 
pessoas significativas (CABRAL, 2015) na composição da ecologia de vida e das convivências das pessoas, grupos ou comunidades. É o que definem alguns autores ao fazerem referência à resiliência comunitária: "Uma vez que a resiliência comunitária consiste nos processos grupais de enfrentamento e adaptação aos desafios coletivos" (OLIVEIRA e MORAIS, 2018, p.1733).

Poderíamos exemplificar a resiliência comunitária através de grupos de pessoas que vivenciaram uma tragédia em comum e procuram juntos estratégias e mecanismos para minimizar o sofrimento (OLIVEIRA e MORAIS, 2018; OJEDA, LA JARA e MARQUES, 2007). Essas concepções e construções sobre os mecanismos promotores da resiliência nos dão suporte para refletir sobre o impacto e operacionalização no contexto profissional e pessoal de formação de professores, dentre outros profissionais. Assim esse cenário pode ser considerado como uma possibilidade de crescimento pessoal, de ajuda mútua e estratégias relacionais que podem oportunizar um espaço de reflexão sobre sua própria prática e seus anseios, suas aflições, seus fantasmas, dentre outros elementos de interferência psíquica negativa.

Apostamos na mediação pela via corporal como uma importante aliada às práticas corporais resultantes do convívio dialógico, cooperativo, interativo e dinâmico das relações, potencializadas pela dimensão protetiva que promove resiliência pessoal frente a situações inesperadas de risco psicossocial. Autores que se dedicam ao estudo dos saberes e da formação docente chamam a atenção para a importância da linguagem corporal e da implicação desta no processo de comunicação interpessoal (TARDIF e LESSARD, 2005; DIESEL, ISSE e SCHWERTNER 2016).

Um dos propósitos da Formação Pessoal pela via corporal é mobilizar o corpo e a mente, momento em que os corpos inquietos se atrelam aos mais delicados e singelos agitos. Outrossim ao expressar gestos grosseiros que representam negatividade dos corpos instruídos, evidenciase a responsabilidade de um professor de Educação Física que aposta na transformação das pessoas pela via corporal. Nossa intenção nesse texto é construir uma proposta que se constitua em possibilidades, para além da sistemática dialógica, no que se refere ao processo de ensino e de aprendizagem no âmbito da Educação Física.

O trabalho foi inspirado nos estudos de Walsh (2005), que aponta alguns processos norteadores na promoção de resiliência familiar que julgamos aplicáveis ao contexto da formação dos acadêmicos. São eles: sistemas de organização; sistemas de crenças e valores; padrões de comunicação. Os processos-chave e as dimensões, apontados por Walsh (2005), descrevem elementos e indicadores que possibilitam ao indivíduo lutar e enfrentar os obstáculos, bem como seguir a vida com mais amor e afeto. 


\section{Contudo é prioritário que mecanismos de mediação protetores auxiliem na superação}

das vulnerabilidades. Por isso argumenta-se que a resiliência pode ser potencializada se este indivíduo contar com outras pessoas, como os familiares, com os amigos ou com os professores. Por meio de vínculos afetivos e das relações promotoras de desenvolvimento (WALSH, 2005), enfatiza-se o elemento relacional do conceito, ou seja, que todos os indivíduos têm a capacidade de desenvolver a resiliência ao longo da vida se encontrarem relações significativas de apoio e afeto em momentos de sofrimento (YUNES; FERNANDES; WESCHENFELDER, 2018).

A resiliência ainda é um conceito permeado por ceticismo por carecer de metodologias claras e rigorosas para identificá-la. A complexidade do construto requer uma ausculta apurada e aprimorada do pesquisador. Apesar dos debates ainda em ebulição no âmbito conceitual e metodológico, os estudiosos da temática apontam para indicadores que se revelam como potencializadores de resiliência. Dentre eles, o aspecto humor chama a atenção por ser um elemento construtor em meio à névoa ou escuridão que, muitas vezes, nos encobre num momento de profundo estresse. O humor desofusca nossa visão e possibilita-nos enxergar algum aspecto positivo que potencializa processos de enfrentamento do sofrimento, dando lugar à resiliência. Alguns autores sinalizam para essa luz que pode representar a esperança quando tudo parece estar perdido. Isso tem profunda relação com proteção e resiliência (VANISTENDAEL, 2013).

O humor é um dos aspectos que tem estreita relação com a psicologia positiva (PALUDO e KOLLER, 2007; YUNES, 2003), pois enaltece as potencialidades e virtudes dos seres humanos e a capacidade de encarar as situações de forma otimista e positiva. Essa atitude e postura nos parecem imprescindíveis dentro do contexto educacional para superação das histórias de adversidades que se apresentam nesse âmbito. Portanto apostamos no eixo do humor criativo e positivo como mais um elemento-chave de proteção para a promoção da resiliência.

No processo de autodesenvolvimento, no que diz respeito ao ato de ser/estar resiliente, está imbricada a possibilidade de promover saúde mental, cuidados e ações frente às situações conflitantes e danosas que podem ir se apresentando ao longo da trajetória de vida. Nessa perspectiva, reiteramos a importância de refletir sobre a contribuição da linguagem corporal como promotora de mecanismos de resiliência em situações individuais caracterizadas por percepção subjetiva de riscos, objetivo desse estudo. 


\section{Caminhos metodológicos}

Os participantes da pesquisa foram 25 alunos do curso de licenciatura em Educação Física de uma universidade do sul do Brasil, durante o $5^{\circ}$ e $7^{\circ}$ semestre. $\mathrm{O}$ grupo era composto por ambos os gêneros com idade entre 22 e 48 anos. Os encontros aconteceram semanalmente com duração de 1h 40min cada. Todos os encontros foram em rodas cooperativas, seguindo os princípios da Formação Pessoal pela via corporal proposta por Negrine (1998). Algumas adaptações foram necessárias para privilegiar o enfoque na promoção de resiliência. Para melhor compreensão e organização dos dados coletados, apresentamos a temática que emergiu no momento da interlocução com as informações em letras maiúsculas, seguidas pelas subcategorias descritas em itálico. No intuito de preservar a identidade dos participantes, estes foram codificados por números, entre 1 até 25 . Seus apontamentos foram descritos em itálico.

Foram utilizados diversos materiais, técnicas, estratégias e dinâmicas para potencializar a linguagem corporal, visando a qualificar a formação dos acadêmicos. Para coleta de dados foram utilizados alguns instrumentos: observações, filmagens e memoriais descritivos. $\mathrm{O}$ estudo foi de cunho qualitativo e optamos pela metodologia Grounded Theory (STRAUSS e CORBIN, 1990), juntamente com o software Atlas.Ti (SAN MARTÍN, 2014; ARIZZA et al., 2015; PISKE, et al., 2018) para a análise das informações. Essa combinação privilegiou a imersão do pesquisador nos dados e a emersão do que foi relevante para o contexto e a pesquisa. A Grounded Theory por meio dos métodos propõe que o pesquisador, em princípio, veja e compreenda o mundo de seus participantes a partir da perspectiva pessoal deles (GLASER e STRAUSS, 1967).

As sessões da Formação Pessoal pela Via Corporal desenvolvidas com os estudantes seguiram os princípios metodológicos, sugeridos por Negrine (1998): rito de entrada, atividade propriamente dita, sensibilização, registro, rito de saída, que passamos a relatar.

Rito de entrada: momento inicial, no qual todos os participantes se sentavam em círculo e o professor explicava a temática da aula, as atividades que seriam realizadas, bem como o material, o espaço e o tempo disponíveis para o encontro. Portanto esse foi o momento de fazer combinados que deveriam ser respeitados no decorrer da sessão, como por exemplo: o respeito e o cuidado com o colega, a observação dos sentimentos que afloram em si durante as ações e inter-relações etc. Em seguida o professor autorizava os alunos a realização das atividades.

Atividade propriamente dita: nesta etapa foram propostas atividades corporais com foco no movimento e na implicação do corpo. Para exemplificar as vivências e caracterizar cada um 
dos momentos, tomaremos por base a aula sobre confiança nas inter-relações para poder explicar os pormenores. No primeiro momento, os alunos realizaram a atividade do nó humano. A atividade se inicia em círculo, e cada um dos participantes deve observar quem está à sua direita e à sua esquerda. O grupo deve circular pelo ambiente e, ao sinal do professor, aproximar-se novamente de forma aleatória. E, da posição de onde estiverem, devem pegar a mão do colega que estava à direita e o da esquerda no círculo anterior. Forma-se nesse momento um nó humano que deverá ser desfeito formando novamente um círculo. Em seguida, nessa aula, realizamos algumas atividades de coordenação motora em duplas e depois trios, no intuito de promover o diálogo, a escuta, o toque e o olhar para o outro.

No segundo momento, os participantes foram organizados em duplas, sendo que um deles estava de olhos vendados e o outro o conduzia pelo interior da sala alternando o ritmo, ou seja, em alguns momentos devagar; em outros, acelerado, com paradas bruscas, giros, sentava etc. O professor também provocava a troca de pares para vivenciar ritmos, toques e orientações diferentes. Na sequência da aula, a atividade proposta era denominada de joão bobo, a qual era realizada em grupos de cinco alunos. Era o momento em que um aluno ficava ao centro e deixava seu corpo cair em direção aos colegas, os quais deveriam segurá-lo, oferecendo segurança. No primeiro momento, a atividade era realizada de olhos abertos, depois, de olhos vendados. O movimento de cair, segurar e impulsionar o corpo do colega para os demais era executado em diferentes ritmos. Para finalizar a atividade principal, os alunos foram provocados a participar da cama de gato que consiste em dispor os colegas em fileiras uma de frente para a outra, com duplas de mão dadas formando um apoio para que o colega fique deitado sobre os braços dos demais, sendo arremessado para a frente.

As atividades variaram de uma sessão a outra, ora individuais, ora em pequenos grupos, de carácter lúdico e cooperativo. As atividades de mobilização foram realizadas em duplas, utilizando instrumentos mediadores entre um corpo e o outro (bola, corda, bastõesetc.) e por vezes sem estes, favorecendo o contato corporal direto. Tanto em um momento como em outro, a música fez parte do cenário, como elemento propulsor das emoções. O professor utilizou como recurso pedagógico a troca frequente dos pares, dos objetos e dos estímulos emocionais, de modo que cada estudante pudesse vivenciar as atividades com todos os elementos do grupo, ou em outras situações consigo mesmo.

Sensibilização: o trabalho final foi sugerido em duplas. Neste, foi proposto que conversassem sobre as vivências e que cada um falasse para o outro as suas percepções sobre a vivência, procurando não mascarar suas emoções, em especial os desconfortos. Desta forma, 
ao falar em duplas, foi possível diminuir a tensão para falar ao grande grupo, encorajando os participantes ao diálogo grupal. Tal momento foi precedido de uma atividade de relaxamento.

Registro: os participantes elaboraram um memorial descritivo, ou seja, fizeram os registros das emoções vivenciadas. Cada participante escreveu o que foi relevante sobre as vivências.

Rito de saída: momento em que todos os participantes sentaram em círculo e expressaram seus sentimentos e percepções, sem entrar em julgamento de mérito sobre as tarefas propostas. Esse foi um momento de verbalização e o professor adotou uma posição de escuta, sem julgamentos ou apartes.

Como dito anteriormente, foram necessárias adaptações na metodologia descrita por Negrine (1998) para enfatizar os mecanismos promotores de proteção e de resiliência. Nesse sentido, as atividades foram planejadas, oferecidas e conduzidas com foco em situações que levassem os estudantes a vivenciarem situações de angústia, de solidão, de alegria, de conforto, de desconforto, de confiança, de pré-conceito, enfim, múltiplos e variados sentimentos. Muitos desses sentimentos e emoções fizeram com que fatos ou momentos marcantes da vida fossem revisitados, além da reflexão sobre as posturas e comportamentos pessoais e profissionais.

A estratégia promoveu uma ponderação sobre como a pessoa vai se constituindo e como os aspectos e situações positivas e negativas puderam potencializar a resiliência (ou não). Também foi proposta aos estudantes a leitura e posterior discussão de um texto para que o grupo tivesse um embasamento teórico sobre a vivência, a fim de auxiliar na reflexão de sua práxis. As atividades aconteceram numa sala da universidade com $90 \mathrm{~m}^{2}$. No chão havia tatame, fato que oportunizou a prática das atividades descalços, tendo uma porta de acesso e várias janelas a uma altura de $1,80 \mathrm{~m}$. Em uma das paredes havia um espelho de $2 \mathrm{~m}$ de altura e $5 \mathrm{~m}$ de comprimento. No ambiente estava disposto somente o material a ser utilizado na vivência e os equipamentos de som.

\section{Resultados e discussões}

A linguagem corporal é uma das formas mais antigas e naturais de comunicação entre os seres humanos. As sensações e as emoções variam e podem ser transmitidas de várias maneiras: por gestos, pela postura, pelo tom de voz ou até mesmo pelo modo de andar. Tais fatores podem muitas vezes estar relacionados ao medo, à desconfiança, à insegurança, ao tédio, 
à alegria, aos contentamentos, à satisfação e a tantas outras percepções transmitidas pela comunicação não-verbal. Por isso estabelecer um diálogo entre/com o educador e os estudantes é de suma importância, além do olhar atento e a construção de estratégias para o desenvolvimento e manutenção das relações que gerem aprendizagens significativas.

As intervenções realizadas por meio de estratégias pedagógicas resultaram na temática central, linguagem corporal, foco nas emoções e sentimentos, que foram vivenciados e expressados pelos estudantes. Com os mecanismos de promoção da resiliência emergiu a categoria 'vivência positiva da corporeidade' seguida pelas subcategorias, que apresentaremos em seguida.

Na subcategoria vivência da confiança, os estudantes tiveram a oportunidade de deixar o corpo cair e confiar nos colegas com os quais estariam. As emoções foram diversas, conforme podemos acompanhar nos relatos abaixo:

\begin{abstract}
Não senti confiança em quase nenhum momento (...) pouco confiei em suas ações. (...) me senti desconfortável ao deixar minha integridade física nas mãos de outra pessoa (Participante 07). Para mim as atividades de hoje foram ruins, porque eu não consigo confiar neles (os colegas), pois eles não me inspiram confiança. Eu não sei como funciona para eu confiar nas pessoas, mas acredito que isso tenha que ser construído, conquistado (Participante 03). As atividades nos sensibilizaram perante a este tema e nos percebemos enquanto seres de confiança e passamos este sentimento aos nossos colegas. Experienciamos diferentes sensações que me trouxeram um bem-estar muito grande (Participante 01).
\end{abstract}

As experiências foram significativas no que tange ao fortalecimento de mecanismos de proteção, quando os estudantes se sentiram inseguros frente às diversas situações. Para tantoos estudantes precisaram superar medos e estabelecer vínculos de confiança antes que se sentissem seguros. Krueger $(2002$; 2001) corrobora essa linha reflexiva, quando afirma que algumas experiências corporais são especialmente positivas e vinculam o indivíduo à sua realidade corporal, potencializando que ele se aceite e reconheça suas fragilidades. E, a partir daí, maneje suas vulnerabilidades.

A vivência do escutar se tornou uma experiência significativa para a grande maioria dos estudantes e foi uma motivação para a reflexão de suas intra e inter-relações (consigo mesmos e com seus pares), conforme podemos acompanhar no relato:

Eu gosto de ouvir os outros, pois assim é possível conhecê-los. Mas aqui (no curso) parece que nos escutamos pouco, pois pouco nos conhecemos (...) todos querem ser escutados, mas ninguém quer ouvir (Participante 03). Alguns colegas também me emocionaram ao relatar momentos da infância e seus

Revista Interinstitucional Artes de Educar. Rio de Janeiro, V. 5, N.3-pág. 596-611 set-dez de 2019: "Educação: Corpo em movimento." - DOI: 10.12957/riae.2019.45597 
relacionamentos afetivos. Colegas que conheço, mas nem imaginava que tinham estas histórias de vida (Participante 21). Hoje resgatamos muitas lembranças da nossa infância, adolescência, que me emocionaram demais. Muitas destas lembranças estavam desaparecidas dentro de mim e dos meus pensamentos (Participante 02).

Ouvir o relato do outro, e refletir sobre a experiência do colega, pode empoderar o estudante. Isso o encoraja a enfrentar situações adversas semelhantes ou propicia um repertório de conhecimento para enfrentamentos futuros. Remete-se assim a uma postura solidária e empática, de se colocar no lugar do outro e tentar compreender o que o outro sentiu. Dialogar e vivenciar situações que tragam à tona dificuldades pessoais em um espaço seguro e orientado para tal finalidade, pode representar a possibilidade de se deslocar de uma condição passiva, frente às situações adversas, para outra ativa. Nessa nova condição, a pessoa passa a operar sentimentos, emoções e transformá-los em mecanismos de proteção edificantes, fundamentais para a dimensão da resiliência.

Outra subcategoria que emergiu dos discursos nos proporcionou pensar sobre a vivência dos rótulos e pré-conceitos. Nesta, os estudantes puderam expor constrangimentos, préconceitos, humilhações, bullying e outras situações, conforme anotamos:

Acredito que se ficarmos presos aos rótulos perdemos uma grande oportunidade de conhecer o lado bom ou até o lado desconhecido, mais precioso e íntimo das pessoas com as quais convivemos. (...) acho que se meus colegas se despissem dos pré-conceitos que têm em relação a mim, conheceriam uma pessoa que eles nem sonham que existe (Participante 10). Falando sobre os rótulos e pré-conceitos que conseguiremos desmitificá-los, e aumentar as possibilidades das pessoas se socializarem. Olha quanta coisa falamos hoje em aula sobre nós e isso de alguma forma vai nos aproximar de nós mesmos e de nós enquanto grupo (Participante 05).

Embora seja complexo trazer à tona temáticas como a de rótulos, é extremamente necessário tratar esses aspectos considerados negativos nas relações. São questões que estão imbricadas nos âmbitos escolares, às vezes de forma velada, outras de forma mais expositiva. Não é raro ouvir relatos de professores que consideram os alunos como sendo casos perdidos, esse não aprende ou esse não tem jeito. Estes são fatores que influenciam e interferem na aprendizagem do aluno.

O ser humano rotula com adjetivos e pré-conceitua sem problematizar questões fundamentais, ficando evidente a necessidade de o educador questionar, contextualizar e dialogar sobre preconceitos, muitas vezes imputados aos estudantes desde muito cedo em suas Revista Interinstitucional Artes de Educar. Rio de Janeiro, V. 5, N.3- pág. 596-611 set-dez de 2019: "Educação: Corpo em movimento." - DOI: 10.12957/riae.2019.45597 
vidas. Adjetivos e rótulos pejorativos constituem bullying, e há muitos estudos recentes sobre esse tema (YUNES e FERNANDES, 2018). Saber lidar com esses fatores no processo de ensino e aprendizagem é também tarefa do professor. São questões diretamente relacionadas a risco psicossocial, proteção e resiliência, os quais podem ser articulados com os padrões de organização e de comunicação cunhados por Walsh (2005).

Os participantes, em sua maioria, estudavam juntos há 7 semestres, porém nunca tinham trocado abraços ou um toque carinhoso. Tal fato motivou o seguinte relato de um dos participantes: "antes éramos uma turma, agora ao final dessa experiência conhecemos nosso colega e somos amigos, nos ajudamos mais, estamos tendo momentos de confraternizações fora da universidade. Agora posso dizer que o curso me trouxe amigos, alguns para a vida toda". (Participante.13). Tais registros nos levam a inferir que as vivências são edificantes e podem favorecer mecanismos de proteção promotores de desenvolvimento.

No contexto acadêmico, ao analisarmos, com as lentes das emoções, as adversidades são de natureza variada, mas não significa, de forma alguma, que são insuperáveis. Pelo contrário, a quantidade e qualidade das adversidades podem significar o fortalecimento dos mecanismos promotores da resiliência. Cada adversidade superada pode significar mais solidez nas interrelações e fortalecimento para o enfrentamento da próxima situação adversa. A superação ou a fragilidade da pessoa diante das situações vai depender muito mais das estratégias utilizadas para o enfrentamento do que da qualidade ou quantidades de adversidades.

É pelo corpo que o ser humano adquire consciência do mundo e de si mesmo: percepção da objetividade e da subjetividade. O corpo é, portanto, o organismo de relação e reflexão sobre o ambiente e sobre si próprio. Nessa perspectiva apresentamos a expressão corporal das emoções. Essa foi enfatizada pela vivência do espelho, momento em que os alunos demonstraram e expressaram diversos sentimentos, tais como: tristeza, angústia, medo, alegria, euforia etc. Conforme registros dos participantes:

Quando desenhamos utilizando o nosso corpo me percebi desenhando problemas e tristezas, mas não era o que eu queria. Simplesmente fluiu (Participante 07). A linguagem corporal trabalha nosso eu mais interior, nossa essência, nossas vontades, sentimentos, sensações mais intrínsecas, mais aprofundadas do ser humano (Participante 12). Percebi que não costumo expressar o que sinto [...] estou acostumada a tentar esconder esses sentimentos (Participante 05).

A forma de perceber o mundo e seus fenômenos está ligada diretamente à sociedade e à cultura. E por meio desta percepção não se pode afirmar que a razão do ser está estruturada Revista Interinstitucional Artes de Educar. Rio de Janeiro, V. 5, N.3- pág. 596-611 set-dez de 2019: “Educação: Corpo em movimento." - DOI: 10.12957/riae.2019.45597 
biologicamente, uma vez que o corpo pode ter os mesmos componentes biológicos. Porém, a percepção de mundo através do seu espaço vivido pode torná-lo diferente. São as diversas influências dos distintos ambientes que constituem o sujeito, para além da sua bagagem genética. Assim, a percepção mediante a corporeidade também é social e culturalmente modelada, porque a corporeidade entende que o ser humano é um ser único, estruturado por meio de suas vivências (MERLEAU-PONTY, 1994).

Walsh (2005) alerta que a desordem psicofísica pode aumentar quando elementos estressantes cotidianos reativam recordações e emoções negativas do passado (WALSH, 2005). Portanto, é preciso ter cautela ao provocar a pessoa a relembrar fatos dolorosos. Mexer nas feridas pode ser danoso ao desenvolvimento dos sujeitos. Ao mesmo tempo, não se deve negar o que foi vivido por eles, mas sim compreender e tornar-se reflexivo e positivo diante dos fatos. Pode parecer paradoxal e é essa medida que exige grande esforço e sensibilidade do professor. É importante saber aguardar a prontidão de cada um para externar seus conflitos internos. Para esse momento o professor deve estar atento e fazer o papel de mediador, utilizando-se dessa situação como oportunidade, para além de estabelecer um vínculo, orientar e apoiar a pessoa numa relação de afetividade e acolhimento.

É no contexto da Formação Pessoal que o adulto aprende a ter mais disponibilidade corporal, conhece melhor suas limitações e ao mesmo tempo refletir sobre elas. Esse autoconhecimento oportuniza a percepção de algumas resistências e favorece posterior desbloqueio; permite uma dimensão mais real das limitações de cada indivíduo frente a diferentes situações. Consequentemente, prepara o profissional para ter uma postura de escuta em relação ao aluno, melhorando assim a compreensão e seu relacionamento com ele (NEGRINE,1998).

As sessões de Formação Pessoal utilizaram a ludicidade. Na fronteira de seus limites, os estudantes foram ampliando sua disponibilidade e suas possibilidades num clima de permissividade, criatividade, interação e segurança, o qual podemos acompanhar no exemplo da experiência pelo toque corporal. Os estudantes foram estimulados a tocar em seus colegas, inicialmente com os olhos vendados e depois sem a venda, sem o uso das palmas das mãos, parte do corpo mais utilizada para manipular, permitindo a exploração de outras possibilidades de contato e sensações. As expressões nas faces foram diversas: riso, constrangimento, angústia, relaxamento, sentimentos expressados (?), o que também foi confirmado nos memoriais: 
Muitas vezes me senti entusiasmada com as atividades, penso que sou necessitada de um toque de carinho, ou simplesmente de um toque qualquer. Sinto falta do toque e carinho na minha família, pouco nos abraçamos. Não sei o porque disto, mas era para mim uma barreira grande a qual sempre quis quebrar (Participante 18). Acredito que criamos um vínculo ótimo quando nos tocamos e nos abraçamos, seja com colegas, familiares ou alunos (participante 07). Trabalhamos o toque (...) a sensação de paz, alívio e descanso corporal veio provavelmente aliado a intenção do toque (...) a aula de hoje foi muito energizante (participante 01).

Perceber o outro por meio do toque colocou os estudantes numa posição sensível e eles tiveram uma aproximação do sentir, que muitas vezes, no campo acadêmico, pode ser esquecido ou sufocado por rendimentos mensuráveis. Isso somente foi possível por meio da práxis, pelo processo de ação e reflexão (FREIRE, 1996). Tivemos como resultado uma nova ação, resultado alcançado por meio da transformação dos estudantes envolvidos na formação pela via corporal, com vistas à promoção da resiliência.

Constatamos que a disciplina possibilitou uma articulação entre a psique e o físicomotor, junção indissociável ao considerar as individualidades e as construções coletivas, conectadas às aprendizagens dos estudantes, que vivenciaram o desenvolvimento humano como um processo permanente.

A Formação Pessoal pela Via Corporal não buscou apenas formar educadores, mas tornar humanos mais humanos (BRONFENBRENNER, 2011), com percepções mais sensíveis e olhares cada vez mais cuidadosos para consigo mesmos e com seus pares, nos diversos contextos. Consequentemente, superam-se as adversidades, mobilizando a capacidade de resiliência.

Na tentativa de minimizar ou sanar os conflitos frente às situações inesperadas, a linguagem corporal potencializou mecanismos de proteção com vistas à promoção de resiliência. Diante disso, episódios traumáticos e dolorosos foram encarados sob outra ótica, podendo ser transformados em verdadeiras lições de vida, resultando numa forma de proteção ao estado físico, cognitivo e comportamental.

Sendo assim, potencializar a resiliência implicou reconhecer os próprios conflitos e experimentar uma vivência corporal em ambiente de segurança e proteção, adequados à reflexão e ao enfrentamento.. 


\section{Considerações finais}

As estratégias foram cuidadosamente conduzidas, orientadas pelos princípios da Formação Pessoal pela Via Corporal, com vistas ao desenvolvimento de mecanismos de proteção para processos de resiliência no âmbito acadêmico. As categorias apresentadas foram construídas e alicerçadas com os estudantes numa permuta de interação, cooperação e diálogo ao oportunizar, exteriorizar sentimentos e recordar situações traumáticas do passado ou até mesmo vivenciadas no ambiente acadêmico, sendo compartilhadas em dinâmicas pela via corporal.

A linguagem corporal se tornou um mecanismo de proteção para solidificar vínculos e promover resiliência em situações de risco. Foi apontada pelos acadêmicos como uma possibilidade de inter-relação com a vida em seus diferentes aspectos. Segundo os participantes da disciplina Formação Pessoal pela Via Corporal, os princípios compartilhados pelas vivências cooperativas foram essenciais, já que privilegiaram a livre expressão, o diálogo e a maneira de (re)agir sobre seus dilemas e conflitos, sendo aliadas nas possibilidades de trazer processos de resiliência pela via corporal, já que foi e é apontada como uma estratégia interativa sobre os condicionantes socioambientais que envolvem a vida e o desenvolvimento humano.

Por fim, cabe ressaltar que as experiências foram vistas como rupturas de práticas individualistas e isoladas em prol das coletivas. Os acadêmicos expressaram que, no momento de partilhar e compartilhar, perceberam que não eram tão isolados como pensavam. Tiveram a oportunidade de interagir com outros, coletivamente. Os resultados obtidos apontaram possibilidades de mudanças, segundo os argumentos, devido ao fator potencializador da resiliência pela via corporal. Tal ação foi implicada pelas aprendizagens compartilhadas e atreladas à relação humana coletiva, na qual juntos construíram possibilidades de superação diante das adversidades expostas. A linguagem corporal como mecanismo de proteção para promoção de resiliência propiciou que os acadêmicos do curso de Educação Física percebessem a necessidade de reaprender a tocar, de olhar no olho e de se sensibilizar com o outro.

\section{REFERÊNCIAS}

ARIZZA, L; DIAS. V; SOUSA. R.; NUNES. B.; GALIAZZI, M. C.; SCHIMIDT, E. B. Articulações metodológicas da análise textual discursiva com o Atlas.Ti :compreensões de uma comunidade aprendente. $4^{\circ}$. Congresso Ibero Americano em Investigação Qualitativa, Universidade Tiradentes, Aracaju- Brasil, 2015. Disponível em

Revista Interinstitucional Artes de Educar. Rio de Janeiro, V. 5, N.3- pág. 596-611 set-dez de 2019: "Educação: Corpo em movimento." - DOI: 10.12957/riae.2019.45597 
<http://proceedings.ciaiq.org/index.php/ciaiq2015/article/view/273>. Acesso em: 05 de jan. 2016.

BERSCH, A.A.S. A formação pela via corporal dos educadores sociais nas instituições de acolhimento: intervenções para a promoção da melhoria das interações. ANAIS X ANPED SUL, Florianópolis, outubro de 2014. Disponível em: http://xanpedsul.faed.udesc.br/arq_pdf/1768-0.pdf. Acesso em 17 de jun.2019.

BORGES, C.N.F.; LOPES, S. M.; ALVES, C.A.; ALVES, F.P. Resiliência: Uma Possibilidade de Adesão e Permanência na Prática do Futebol Feminino. Revista Movimento, Porto Alegre, v.12, n. 01, p. 105-131, janeiro/abril. 2006. Disponível em: http://www.seer.ufrgs.br/index.php/Movimento/article/view/2893/1529. Acesso em: 20 abr. 2016.

FONTES, R. C. C. \& BRANDÃO, M. R. F. A resiliência no âmbito esportivo: uma perspectiva bioecológica do desenvolvimento humano. Revista Motriz, Rio Claro, v.19 n.1, p.151-159, jan./mar. 2013. Disponível em:

http://www.scielo.br/pdf/motriz/v19n1/a15v19n1.pdf. Acesso em: 12 de jul. 2019.

BRONFENBRENNER, U. Bioecologia do desenvolvimento humano: tornando os seres humanos mais humanos. Tradução André de Carvalho-Barreto. Porto Alegre: Artmed, 2011.

CABRAL, S. Marcas de resiliência ou sobre como tirar leite de pedra. In: CABRAL, S. \& CYRULNIK, B. (orgs.) Resiliência: como tirar leite de pedra. São Paulo: casa do psicólogo, 2015.

CHARMAZ, K. A. Construção da Teoria Fundamentada: guia prático para análise qualitativa. Porto Alegre: Artmed, 2009.

DIESEL, D.; ISSE, S. SCHWERTNER, S. A importância de uma formação pessoal e corporal do futuro professor de educação física. Seminário Nacional de Pesquisa em Educação, Universidade de Santa Cruz do Sul, 2016. Anais... ISSN 2359-0963. Disponível em: https://online.unisc.br/acadnet/anais/index.php/sepedu/article/view/14810. Acesso: 17 set. 2019.

FONTES, R.C.da C.; BRANDAO, M.R.F. A resiliência no âmbito esportivo: uma perspectiva bioecológica do desenvolvimento humano. Motriz: Revista Educação Física, vol.19, n.1, pp.151-159, 2013. ISSN 1980-6574. Disponível em:

http://dx.doi.org/10.1590/S1980-65742013000100015. Acesso em: 22 fev.2016.

FREIRE, P. Pedagogia da autonomia: saberes necessários à prática educativa. São Paulo: Paz e Terra, 1996.

GLASER B. G.; STRAUSS, A. L. The discovery of grounded theory. New York: Aldine, 1967.

KRUEGER, D.W. Body Self: Development, Psychopathologies and Psychoanalytic Significance. Psychoanalitic Study of Child, 56, 238-262, 2001. 
KRUEGER, D.W. Integrating Body Self and Psychological Self: creating a new history in psychoanalysis and psychotherapy. Nova lorque: Brunner-Routledge, 2002.

MARTINEAU, S. Rewriting resilience: a critical discourse analysis of childhood resilience and the politics of teaching resilience to "kids at risk". Tese de Doutorado nãopublicada, The University of British Columbia, 1999.

MASTEN, A. S. Ordinary magic: Resilience in development. New York, NY: Guilford, 2014.MERLEAU-PONTY, M. Fenomenologia da percepção. São Paulo: Martins Fontes, 1994.

NEGRINE, A. Terapias corporais: a formação pessoal do adulto. Porto Alegre: Edita, 1998.

NEVES, A. N.; HIRATA, K. M; TAVARES, M.da C.G.C.F. Imagem corporal, trauma e resiliência: reflexões sobre o papel do professor de Educação Física. Revista

Quadrimestral da Associação Brasileira de Psicologia Escolar e Educacional, SP. Volume 19, Número 1, Janeiro/Abril de 2015: 97-104. Disponível em: http://www.scielo.br/pdf/pee/v19n1/2175-3539-pee-19-01-00097.pdf. Acesso: 15 jul.2019.

OLIVEIRA A.T.C.; MORAIS N.A.. Resiliência Comunitária: um estudo de revisão interpretativa da literatura. Trends Psychol., Ribeirão Preto, vol. 26, no 4, p. 1731-1745 Dezembro/2018. Disponível em: http://www.scielo.br/pdf/tpsy/v26n4/2358-1883-tpsy-26-041731.pdf. Acesso: 14 set. 2019.

OJEDA, E.N.S.; LA JARA, A.; MARQUES. C. Resiliência Comunitária. In: HOCH, C.; ROCCA, S. Sofrimento, Resiliência e Fé - Implicações para as relações de cuidado. São Leopoldo: Editora Sinodal, 2007, 97p.

PALUDO, S.S.; KOLLER, S. Psicologia Positiva: uma nova abordagem para antigas questões. Paidéia, v.17, n.36, p. 9-20, 2007. Disponível em:

http://www.scielo.br/pdf/paideia/v17n36/v17n36a02.pdf. Acesso em: 13 de ago.2019.

PISKE, E. L.; YUNES, M. A. M.; BERSCH, A. A. S.; PIETRO, A. T. Práticas educativas nas instituições de acolhimento sob o olhar das crianças. $R$. Educ. Públ. Cuiabá: UFMT, v. 27 n. 66, p. 905- 923, 2018. Disponível em:

http://periodicoscientificos.ufmt.br/ojs/index.php/educacaopublica/article/view/3364/pdf. Acesso em: 27 set. 2019.

SAN MARTÍN, D. Teoría fundamentada y Atlas.ti: recursos metodológicos para la investigación educativa. Revista Electrónica de Investigación Educativa, v.16, n.1, p.104122, 2014. Disponível em:

http://www.scielo.org.mx/scielo.php?script=sci_arttext\&pid=S1607-40412014000100008. Acesso 23 jul.2019.

STRAUSS, A.L.; CORBIN, J. Basics of Qualitative Research: Grounded Theory, Procedures and Techniques. Newbury: SAGE, 1990.

TARDIF, M.; LESSARD, C. O trabalho docente: elementos para uma teoria da docência como profissão de interações humanas. Petrópolis: Vozes, 2005.

Revista Interinstitucional Artes de Educar. Rio de Janeiro, V. 5, N.3-pág. 596-611 set-dez de 2019: "Educação: Corpo em movimento." - DOI: 10.12957/riae.2019.45597 
VANISTENDAEL, S. La vida no nos sonríe: reflexiones sobre El humor, La resiliencia y La espiritualidad. In: VANISTENDAEL, S.; GABERAN, P.; HUMBEECK, B.; LECOMTE, J.; MANIL, P.; ROUYER, M. Resiliencia y humor. Barcelona: Editora Gedisa, 2013.

WALSH, F. Fortalecendo a resiliência familiar. São Paulo, SP: Roca, 2005.

YUNES, M. A. M. Dimensões conceituais da resiliência e suas interfaces com risco e proteção. In: MURTA, S.G.; FRANÇA, C.L.; BRITO, K.; POLEJACK, L. (Org.). Prevenção e Promoção em Saúde Mental: Fundamentos, Planejamento e Estratégias de Intervenção. $1^{\text {a }}$ ed. Novo Hamburgo: Synopisis, p. 93-112, 2015.

YUNES, M. A. M. Psicologia Positiva e Resiliência: foco no indivíduo e na família. Psicologia em estudo, Maringá,V.8, n. esp., p.75-84, 2003. Disponível: http://www.scielo.br/pdf/pe/v8nspe/v8nesa10.pdf. Acesso em: 28 dez.2018.

YUNES, M. A. M. A questão triplamente controvertida da resiliência em famílias de baixa renda. Tese de Doutorado não-publicada, Programa de Pós-Graduação em Psicologia da Educação, Pontifícia Universidade Católica de São Paulo, São Paulo. 2001. Disponível em: https://tede2.pucsp.br/handle/handle/16345. Acesso em: 12 fev. 2019.

YUNES, M. A. M.; FERNANDES, G.; WESCHENFELDER, G. V. Intervenções psicoeducacionais positivas para promoção de resiliência: o profissional da educação como tutor de desenvolvimento. Educação, Porto Alegre, v. 1, n. 1, p. 83-92, jan. -abr. 2018. Disponível em: http://revistaseletronicas.pucrs.br/ojs/index.php/faced/article/view/29766. Acesso: 27 set. 2019.

\footnotetext{
${ }^{\text {i }}$ Doutora e Mestre em Educação Ambiental pelo Programa de Pós-Graduação em Educação Ambiental da Universidade Federal do Rio Grande - PPGEA/FURG. Professora do Instituto de Educação e do Programa de PósGraduação em Educação - IE/PPGEDu/FURG. Coordenadora do Grupos de Estudos e Pesquisa ECOINFÂNCIAS - Infâncias, ambientes e ludicidade. Integrante do Grupo de Pesquisa e Estudos Educação, Cultura, Ambiente e Filosofia - GEECAF; Integrante do Centro de Referência em Apoio às Famílias- CRAF/FURG.Rio Grande/RS. Brasil. E-mail: angelabersch@gmail.com. ORCID: https://orcid.org/0000-0002-1263- $\underline{9309}$
}

\footnotetext{
ii Doutoranda e Mestre em Educação Ambiental pelo Programa de Pós-Graduação em Educação Ambiental da Universidade Federal do Rio Grande- PPGEA/FURG. Pedagoga. Especialista em Educação Infantil pela Universidade Federal de Pelotas- UFPel. Bolsista da Coordenação de Aperfeiçoamento de Pessoal de Nível Superior- CAPES. Colaboradora do Centro de Referência em Apoio às Famílias- CRAF/FURG. Integrante do Grupo de Estudos Ecoinfâncias: infâncias, ambientes e ludicidade. Colaboradora do UEADSL: Plataforma de Eventos do Grupo Texto Livre pela Faculdade de Letras da Universidade de Minas Gerais. Rio Grande/RS. Brasil. E-mail: e.nanny@ hotmail.com. ORCID: http://orcid.org/0000-0003-0933-4835.
} 